\title{
ERRATA
}

Artigo publicado sem o tópico Agradecimento.

\section{Curvas de crescimento para codornas de corte}

\author{
Growth curve for quails
}

\section{Eduardo Silva Cordeiro Drumond ${ }^{\mathrm{I}^{*}} \quad$ Flaviana Miranda Gonçalves $^{\mathrm{II}} \quad$ Rogério de Carvalho Veloso $^{\mathrm{I}}$} Jéssica Miranda Amaral ${ }^{\mathrm{III}}$ Lucília Valadares Balotin ${ }^{\mathrm{III}}$ Aldrin Vieira Pires ${ }^{\mathrm{IV}}$ Joerley Moreira ${ }^{\mathrm{IV}}$

Para html ou pdf, acesse:

http://www.scielo.br/scielo.php?script=sci_arttext\&pid=S0103-84782013001000023\&lng=pt\&nrm=iso\&tlng=pt ou

http://www.scielo.br/pdf/cr/v43n10/a29713cr6551.pdf

'Programa de Pós-graduação em Zootecnia (PPGZOO), Universidade Federal dos Vales do Jequitinhonha e Mucuri (UFVJM), Rodovia MGT, 367, Km 583, n. 5000, Alto da Jacuba, 39100-000, Diamantina, MG, Brasil. E-mail: eduardodrumond@yahoo.com.br.

"Mestre em Zootecnia, PPGZOO, UFVJM, Diamantina, MG, Brasil.

IIICurso de Zootecnia, Departamento de Zootecnia (DZO), UFVJM, Diamantina, MG, Brasil.

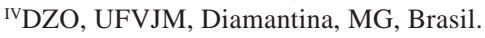

